\title{
[RE]IMAJI GLODOK MELALUI ECHOLOGY
}

\author{
Vito Wijaya ${ }^{1)}$, Maria Veronica Gandha ${ }^{2)}$ \\ 1)Program Studi S1 Arsitektur, Fakultas Teknik, Universitas Tarumanagara, vitowijaya82@yahoo.com \\ 2)Program Studi S1 Arsitektur, Fakultas Teknik, Universitas Tarumanagara, mariag@ft.untar.ac.id
}

\begin{abstract}
Abstrak
Sebuah Arsitektur dapat menjadi penyimpan memori dari suatu masa. Banyaknya bangunan atau kawasan yang memiliki nilai historis kini terbengkalai, terdisintegrasi, tergerus perkembangan moderen. Sejalan dengan perkembangan kota, banyak nya sejarah kelam dan isu-isu politik yang menimpa budaya serta masyarakat Tionghua di Indonesia. Dengan dicabutnya Inpres Nomor 14 Tahun 1967 tentang Agama, Kepercayaan, dan Adat Istiadat Cina pada masa Reformasi digantikan dengan terbitnya Keputusan Presiden (Keppres) Nomor 6 Tahun 2000 pada 17 Januari 2000 membuat budaya Tionghua kembali hidup, kemudian bagaimana sebuah Arsitektur dan sebuah kawasan Pecinan mampu menyesuaikan dengan kondisi pada zaman ini dan untuk masa depan tanpa kehilangan jati diri serta nilai sejarahnya. Proyek ini merupakan perwujudan baru bagi sebuah kawasan yang mencakup berbagai unsur seperti sejarah, budaya, ekonomi, utilitas, serta edukasi. Semua aspek tersebut dibentuk secara kolektif dan berkomunitas dengan metode naratif serta mengkoneksikan elemen-elemen yang sudah ada menjadi konsep Echology. [RE]Imaji Glodok menghasilkan sebuah proyek yang mereimajikan kawasan pecinan Glodok dimana aspek sejarah, budaya dan ekonomi dapat tercerminkan dan membangun imaji Glodok yang baru dengan mempertimbangkan berbagai elemen yang ada pada kawasan serta merancangnya demi keberlangsungan di masa kini maupun masa depan melalui Echology.
\end{abstract}

\section{Kata kunci: Glodok; Imaji; Pecinan}

\begin{abstract}
An Architecture can be a memory store from a time. Many buildings or areas that have historical value are now abandoned, disintegrated, eroded by modern developments. In line with the development of the city, there are many dark histories and political issues that afflict Chinese culture and society in Indonesia. With the revocation of Presidential Instruction No. 14/1967 concerning Chinese Religion, Belief, and Customs during the Reformation period, it was replaced by the issuance of Presidential Decree (Keppres) No. 6/2000 on January 17, 2000, bringing Chinese culture back to life, then how can an Architecture and a Chinatown be able to adapt to the conditions of today and for the future without losing its identity and historical value. This project is a new embodiment for an area that includes various elements such as history, culture, economy, utilities, and education. All these aspects are formed collectively and in a community with a narrative method and connect existing elements into the concept of Echology. [RE]Image Glodok produces a project that reimagines the Chinatown area of Glodok where historical, cultural, and economic aspects can be reflected and build a new Glodok image by considering various elements that exist in the area and designing it for the sake of sustainability in the present and the future through Echology.
\end{abstract}

\section{Keywords: Chinatown; Glodok; Image}




\section{PENDAHULUAN}

Perkembangan zaman yang sangat cepat serta banyaknya peristiwa sejarah yang terjadi membuat sebuah Arsitektur tergerus perkembangan moderen. Ruang-ruang tadi diinterpretasikan menjadi jiwa atau memori yang hilang dalam sebuah ruang karena waktu. Dalam konteks kawasan Pecinan yang terdapat di kota-kota besar pada Indonesia saat ini, Banyak diantaranya mulai kehilangan jati dirinya baik menurut segi budaya maupun sejarahnya. Sejalan dengan perkembangan kota dan banyaknya sejarah kelam serta isu-isu politik yang menimpa budaya serta warga Tionghua pada Indonesia. Hal tadi telah terjadi sejak jaman penjajahan Belanda Hingga kerusuhan tahun 1998 yang menjadikan etnis Tionghua menjadi sasaran. Pada masa reformasi Presiden Gus Dur mencabut Inpres Nomor 14 Tahun 1967 tentang Agama, Kepercayaan, dan Adat Istiadat China. Inpres akhirnya dicabut menggunakan terbitnya Keputusan Presiden (Keppres) Nomor 6 Tahun 2000 dalam 17 Januari 2000. Karena Keppres tersebut, warga Tionghoa akhirnya mampu merayakan Imlek atau hari raya lainnya secara terbuka. Hal itu menciptakan budaya Tionghua kembali hidup, kemudian bagaimana sebuah Arsitektur dan sebuah kawasan Pecinan mampu menyesuaikan menggunakan kondisi pada zaman ini dan buat masa depan tanpa kehilangan jati diri dan nilai sejarah-nya.

Proyek ini bertujuan untuk mengimajikan kembali suatu kawasan dengan nilai sejarah dan budaya yang kuat untuk keberlangsungan-nya di masa kini dan juga di masa depan. Proyek ini tidak hanya terbatas pada suatu bangunan melainkan merupakan perwujudan baru bagi sebuah kawasan yang mencakup berbagai unsur seperti sejarah, budaya, ekonomi, utilitas serta edukasi. Semua aspek tersebut dibentuk secara kolektif dan berkomunitas. Proyek ini juga bertujuan untuk meningkatkan kualitas hidup manusia masa depan. Sustainable Development Goals (SDGs) merupakan suatu rencana aksi global yang disepakati oleh para pemimpin dunia, termasuk Indonesia, guna mengakhiri kemiskinan, mengurangi kesenjangan dan melindungi lingkungan. SDGs berisi 17 Tujuan dan 169 Target yang diharapkan dapat dicapai pada tahun 2030. Beberapa dari poin tersebut diterapkan dan menjadi acuan seperti sebagai berikut.
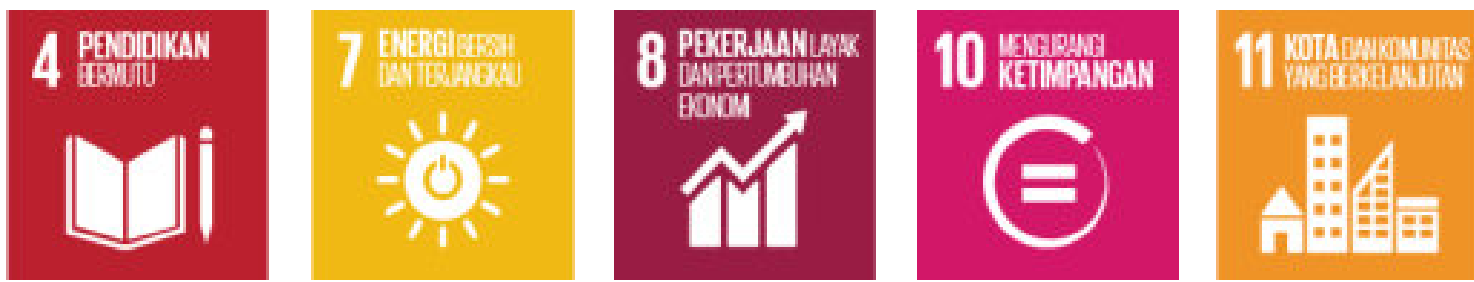

Gambar 1. Acuan Sustainable Development Goal's Perancangan

Sumber: United Nations, 2015

\section{KAJIAN LITERATUR}

\section{The Echology}

Dalam pemrosesan sinyal audio dan akustik, gema merupakan pantulan suara yang sampai pada pendengar dengan jeda setelah suara langsung. Penundaan ini berbanding lurus dengan jarak permukaan pemantulan dari sumber dan pendengar. Contoh tipikal adalah gema yang dihasilkan oleh bagian bawah sumur, oleh bangunan, atau oleh dinding ruangan tertutup dan ruangan kosong. Gema yang sebenarnya adalah pantulan tunggal dari sumber suara. Echo dalam konteks ruang mencoba merekonsiliasi masa lalu yang memiliki nilai historis terhadap masa kini. Usaha ini mencoba membentuk sebuah ruang yang berakar dari sebuah memori dari sebuah ruang baik dari segi visual, perasaan maupun budaya dan kemudian ruang tersebut berusaha memancing sebuah perasaan atau emosional. Sedangkan Echo dalam konteks Arsitektur diibaratkan seperti sebuah objek Arsitektur yang terus memancarkan gaung atau getaran bagi pengguna serta lingkungan sekitarnya. Getaran tersebut mempengaruhi sebuah perasaan, 
perilaku serta memori dari manusia. Sedangkan dalam segi fisik, getaran tersebut mempengeruhi visual, sosok, atmosfir dari sekitar objek tersebut. Sedangkan Echo dalam konteks sebuah kawasan atau beberapa objek Arsitektur diibaratkan seperti sebuah tarian getaran yang dipancarkan dari masing-masing objek, saling mempengaruhi, saling memantulkan, dan membentuk sebuah ekosistem. Penerapan dari teori ini menciptakan sebuah parameter baru dimana elemen-elemen yang saling mempengaruhi pada sebuah tapak dapat menjadi sebuah patokan dalam merancang sebuah ekosistem. Elemen tersebut dapat berupa bangunan fisik, kondisi geografis, kebiasaan masyarakat, stigma sosial, kepercayaan hingga aturan Pemerintah. Teori ini membuat perancang lebih peka dalam menganalisa sebuah kawasan yang memiliki ekosistem.

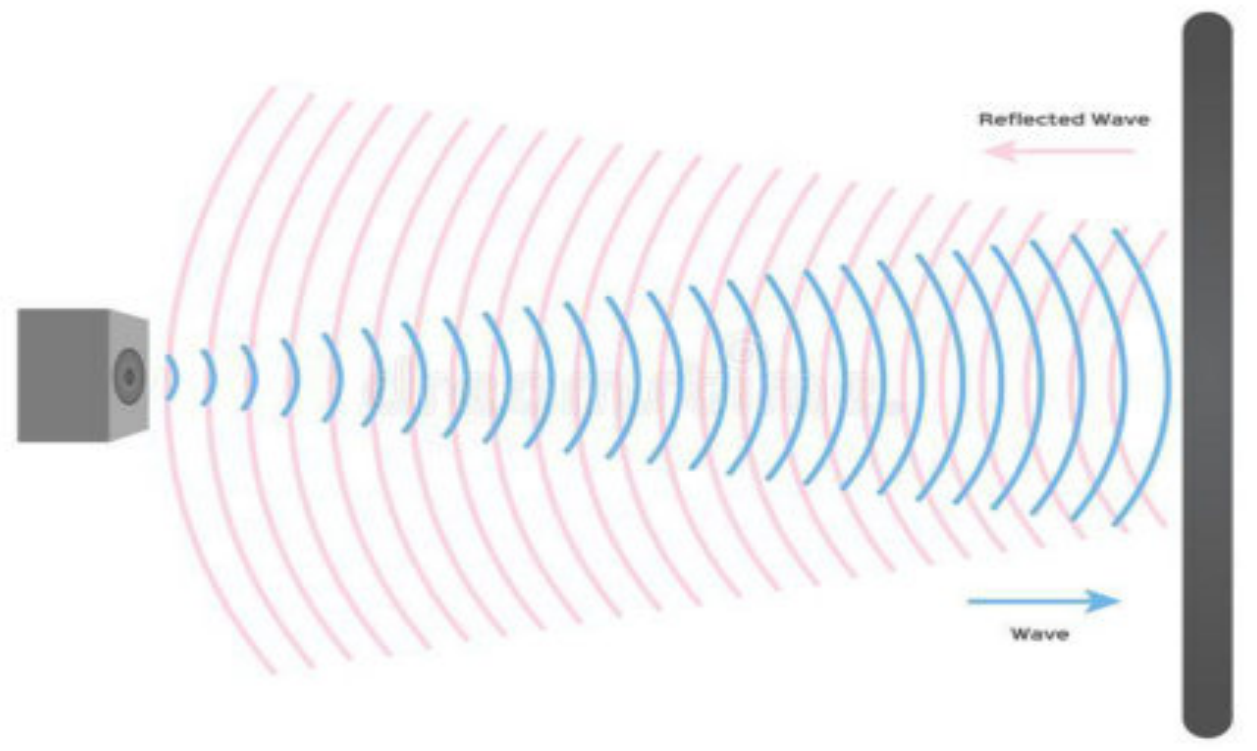

Gambar 2. Ilustrasi Pantulan Gelombang

Sumber: Dreamtimes, 2020

\section{Teori Dawai}

Teori Dawai (String Theory) adalah cabang fisika teoretis yang berkembang, yang menggabungkan mekanika kuantum dan Relativitas Umum menjadi teori gravitasi kuantum. Dawai-dawai dari teori dawai adalah garis berdimensi satu yang bergetar, tetapi mereka tidak lagi dianggap penting untuk teori, yang kini dapat juga dirumuskan dengan titik-titik atau permukaan. Sejak dicetusnya teori tersebut sebagai model talunan ganda yang menggambarkan hadron yang saling berinteraksi dengan kuat sebagai dawai, istilah teori dawai telah diubah untuk mencakup kelompok teori Superstring yang saling berhubungan. Terdapat berbagai formulasi untuk teori dawai, masing-masing dengan struktur matematis yang berbeda, dan masing-masing menjelaskan keadaan fisik berbeda pula.

Namun kemiripan pada asas-asas yang ada pada dari pendekatan-pendekatan ini, konsistensi logis, dan fakta bahwa beberapa dari mereka termasuk model fisika partikel standar, membuat banyak fisikawan percaya bahwa teori dawai adalah teori penjelasan dasar tentang alam semesta yang benar. Secara khusus, teori dawai adalah calon untuk teori segala sesuatu yang paling pertama, salah satu cara untuk menjelaskan semua yang kekuatan alam yang dikenal benda dalam sistem yang lengkap secara matematis. Hal ini juga dapat diterapkan dalam sebuah ekosistem Arsitektur dalam skala mikro-kosmos. Segala unsur yang ada didalamnya saling bergetar dan memberikan resonansi bagi objek lainnya baik secara fisik maupun non-fisik. 


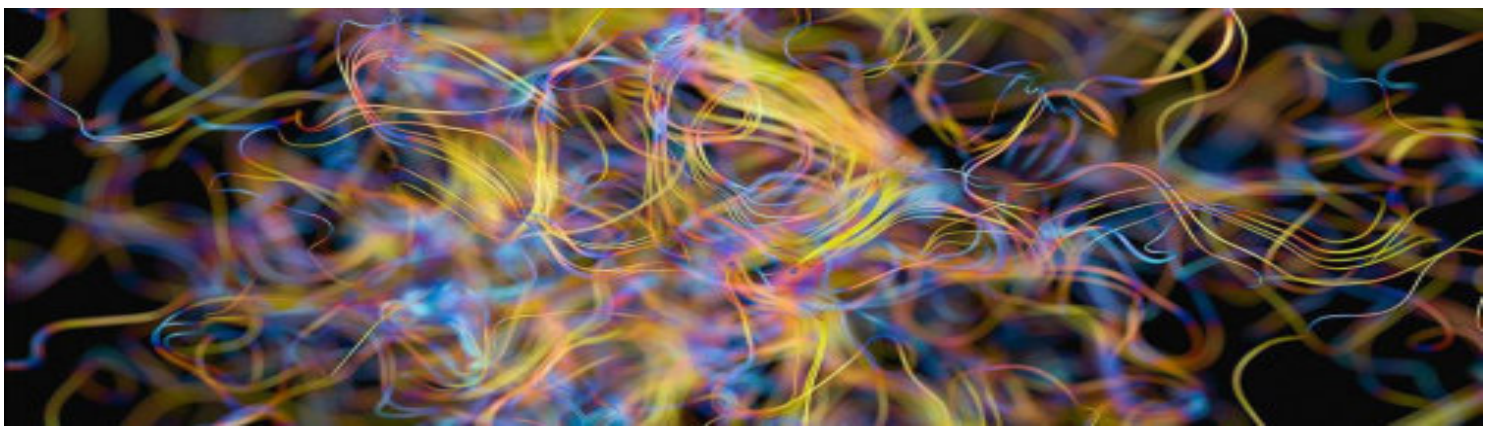

Gambar 3. Ilustrasi Getaran Dawai

Sumber: medium, 2019

\section{Ekosistem Pecinan}

Kawasan Pecinan di daerah perkotaan pada awalnya terbentuk dari warga imigran Tionghua yang mulai berkomunitas. Sejak dulu warga tionghua di berbagai negara selalu bermukim secara berkelompok hingga menciptakan sebuah ekosistem sendiri. Hadirnya kawasan Pecinan dalam perkotaan juga memberikan dampak positif bagi sektor ekonomi, sosial hingga pariwisata. Ciri khas kawasan Pecinan biasanya terlihat dari ornamen Arsitektur yang diadopsi dari Arsitektur tradisional Cina. Terdapat juga gerbang atau Paifang yang menjadi batasan kawasan. Dalam sebuah Pecinan pasti terdapat identitas yang membentuk sebuah citra kawasan pecinan. Unsurunsur yang ada dalam Pecinan dapat diurai dalam teori Kevin Lynch dalam buku The Image of The City. Elemen-elemen dalam kawasan dapat dibagi menjadi 5 unsur seperti Path, edges, district, nodes, landmarks. Semua komponen dalam Pecinan saling mempengaruhi satu sama lain hingga membentuk sebuah jaringan yang menjadi citra bagi kawasan itu sendiri. Aktifitasaktifitas yang ada didalam nya juga beragam dari ekonomi, budaya, kepercayaan, pariwisata hingga politik.

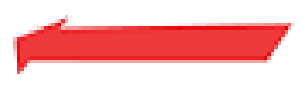

PATH

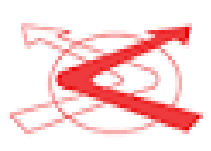

NODE

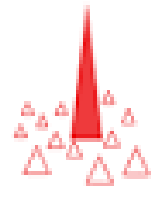

LANDMARK

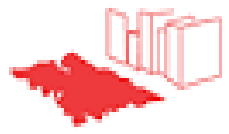

EDGE

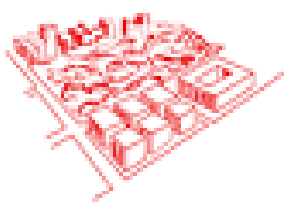

DISTRICT

Gambar 4. Elemen kota Kevin Lynch

Sumber: Researchgates, 2018

\section{Citra Pecinan di Indonesia}

Kawasan Pecinan mempunyai ciri khas yg berisi budaya-budaya Cina baik gaya hidup masyarakatnya juga gaya arsitektur bangunannya. Ciri spesial yg paling mendasar berdasarkan kawasan Pecinan yaitu kelenteng. Kelenteng mempunyai kiprah utama sebagai sentra berkumpulnya komunitas rakyat, dan menjadi simbol pelestarian budaya Cina. Di Indonesia, timbulnya kawasan dengan komunitas rakyat Cina (Pecinan) secara besar-besaran terjadi dalam abad ke-14 yg terletak di wilayah Pantai Utara Jawa. Dalam tatanan ruang kota di Jawa, letak Pecinan yang berada di pusat kota mengakibatkan kawasan ini cenderung strategis. Kawasan Pecinan mempunyai pusat ibadah sendiri yaitu kelenteng serta dekat menggunakan pusat perdagangan misalnya pasar. Kawasan Pecinan dapat dikatakan sebagai kota kecil pada pada sebuah kota, lantaran bangunan-bangunan yang terdapat di kawasan Pecinan cenderung seragam dan dekat menggunakan fasilitas pendukung permukiman yang cukup lengkap. Kawasan Pecinan memiliki kepadatan penduduk yang relatif padat, dan memiliki karakteristik tampilan bangunan berbentuk ruko (tempat tinggal toko). Semua elemen yang ada menjadi parameter dalam menentukan kawasan proyek. 


\section{METODE}

Proses perancangan proyek ini menggunakan metode naratif dalam mendesain bentuk Arsitektur. Sedangkan dalam menentukan program dan letaknya digunakan metode kualitatif. Pencarian data Pada tahapan awal yaitu riset isu hingga pencarian data dan analisis tapak yang didapat langsung dari survei tapak dan berbagai sumber lainnya. Berdasarkan teori yang ada pada kajian literatur, penganalisaan tapak dilakukan secara holistik dan multi dimensional. Elemen- elemen yang ada pada kawasan pecinan menjadi parameter dalam membentuk proyek ini. Daerah pecinan di Indonesia memiliki elemen- elemen pembentuk serta sejarahnya masingmasing. Teori tentang Echo dan teori Dawai menjadi landasan untuk mencari interaksi atau pengaruh masing-masing objek yang ada dalam ekosistem kawasan. Pendekatan dengan metode naratif mencoba mengingatkan sejarah dengan menceritakan sebuah narasi tentang bagaimana perjalanan budaya masyarakat Tionghua di Indonesia terutama di ibukota. cerita ini mencoba mengungkapkan perasaan represif terhadap budaya tionghua yang dulu terdiskriminasi dan dikekang. memahami kontribusi masyarakat Tionghua dalam sejarah yang sejak dulu telah turut membangun masa depan Indonesia. narasi dijadikan ide dalam membentuk sebuah spasial. pengalaman spasial tersebut memicu sebuah perasaan atau interpretasi. mencoba menyampaikan sebuah makna dari sebuah kawasan pecinan dengan menciptakan ruang baru serta mengubah pandangan yang sudah ada. pada massing Culture Centre juga terdapat penerapan metode metafora sebagai acuan dalam membentuk massa dan juga fungsi.

event
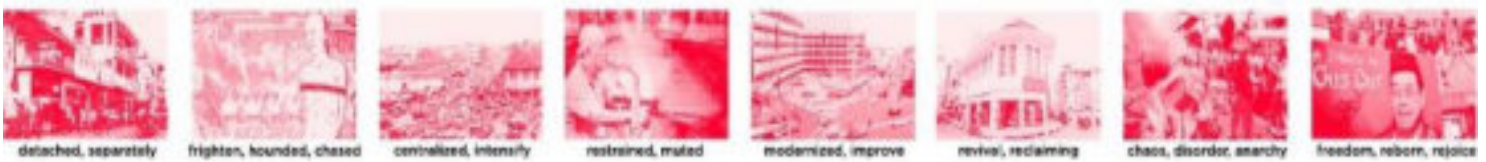

\section{lines}
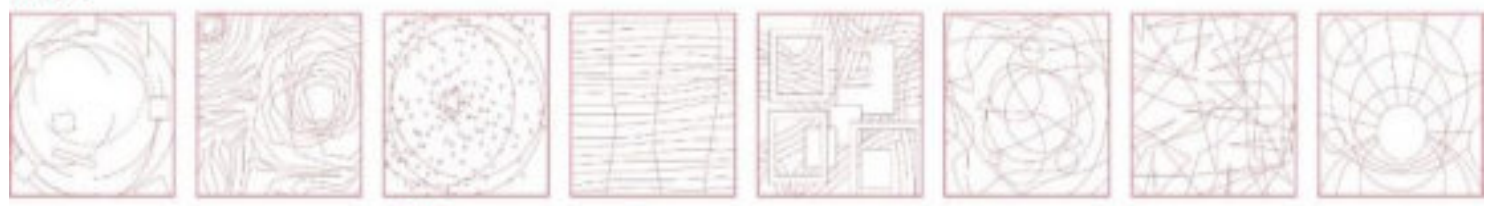

The
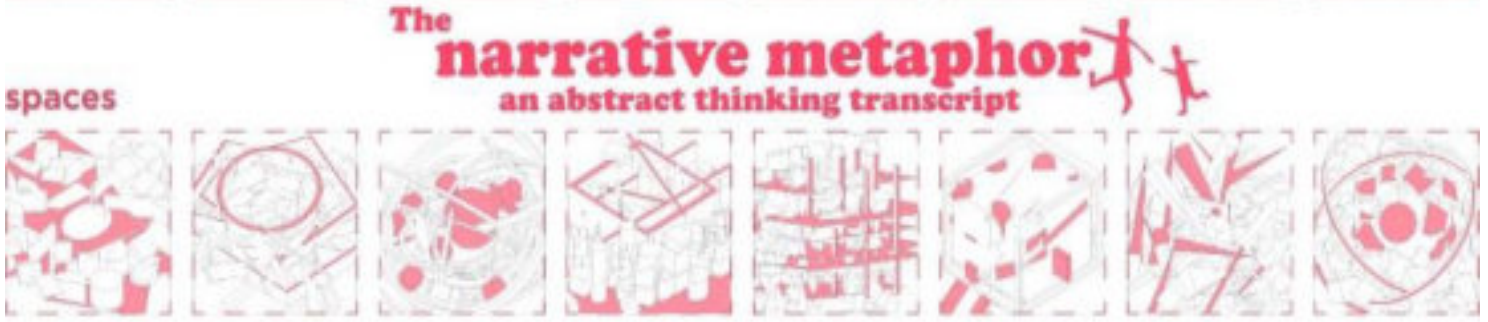

architecture
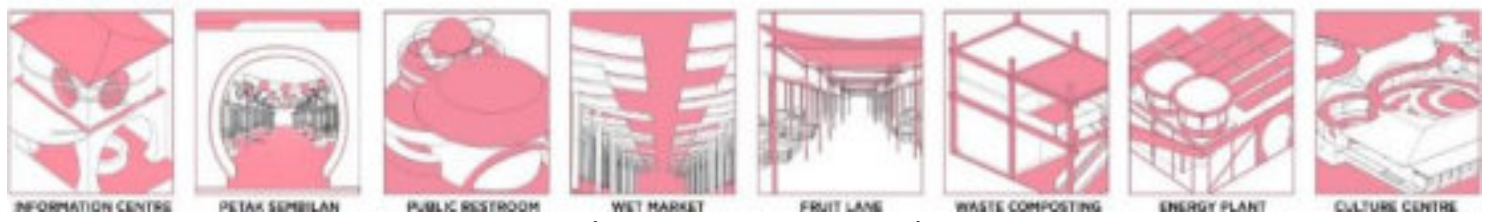

Gambar 5. Diagram Transkrip

Sumber: Hasil olahan penulis, 2021 


\section{DISKUSI DAN HASIL}

Proyek ini merupakan sebuah jaringan yang mencoba menginterpretasikan kembali nilai-nilai sejarah, budaya, ekonomi dalam konteks kawasan pecinan Glodok yang memliki jiwa yang kuat serta masalah yang kompleks dengan mempertimbangkan konteks-nya pada masa lalu, masa kini dan demi keberlangsungan-nya di masa depan. Image Glodok saat ini lebih dianggap sebagai tempat berdagang seperti pasar,Pedagang kaki lima, dll. Lalu, lewat proyek ini saya mereimajikan Glodok menjadi sesuatu yang lebih, dimana aspek sejarah budaya ekonomi dapat tercerminkan dan membangun imaji Glodok yang baru.

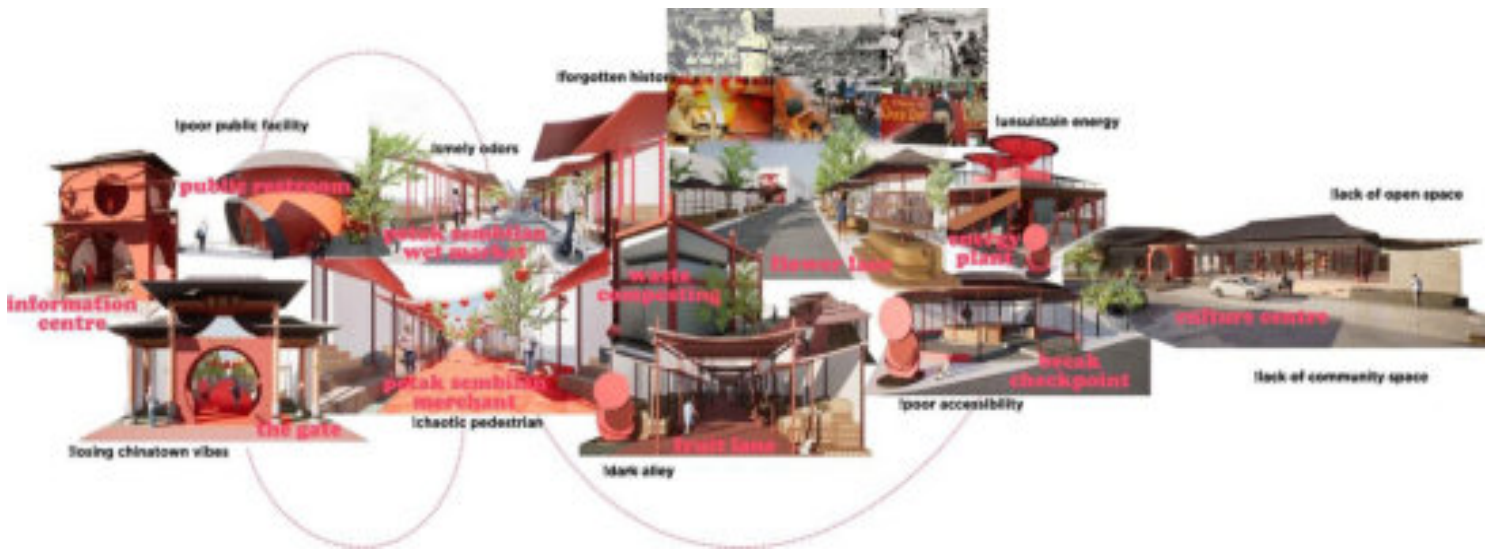

Gambar 6. Ilustrasi [Re]Imaji Glodok

Sumber: Hasil olahan penulis, 2021

\section{Lokasi}

Area Glodok didominasi oleh sektor ekonomi berupa pertokoan, pasar kering, pasar basah, jajanan, hingga PKL. Terdapat 3 akses utama menuju kawasan tapak. Gerbang dari jalan Pancoran hanya dapat dilalui pejalan kaki dengan ketersediaan parkir pada layer luar serta jarak ke transportasi publik yang dekat. Gerbang jalan Kemenangan di prioritaskan untuk kendaraan menuju ke tapak Surface namun tersedia juga Becak Checkpoint sebagai penanda serta fasilitas dalam kawasan. Gerbang jalan Gajah mada sebagai akses dari jalan primer, serta akses langsung menuju halte transjakarta. Terdapat juga beberapa bangunan bersejarah seperti Geraja, Vihara dan kelenteng yang tersebar dalam kawasan. Tapak Surface dengan luasan sekitar $4000 \mathrm{~m}^{2}$ berada pada jantung kawasan dan bersebelahan langsung dengan objek bersejarah yaitu Vihara Dharma Bhakti dan Gereja Santa De Fatima.

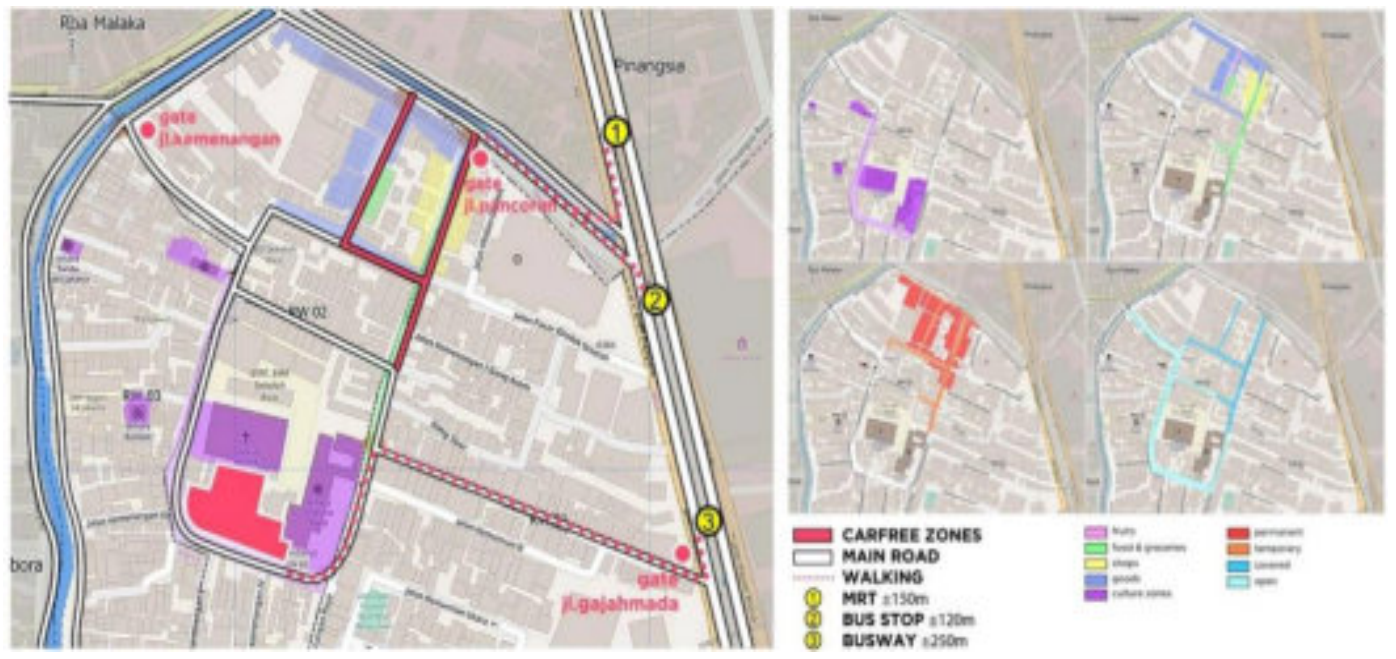

Gambar 7. Diagram Pemetaan Glodok

Sumber: Hasil olahan penulis, 2021 


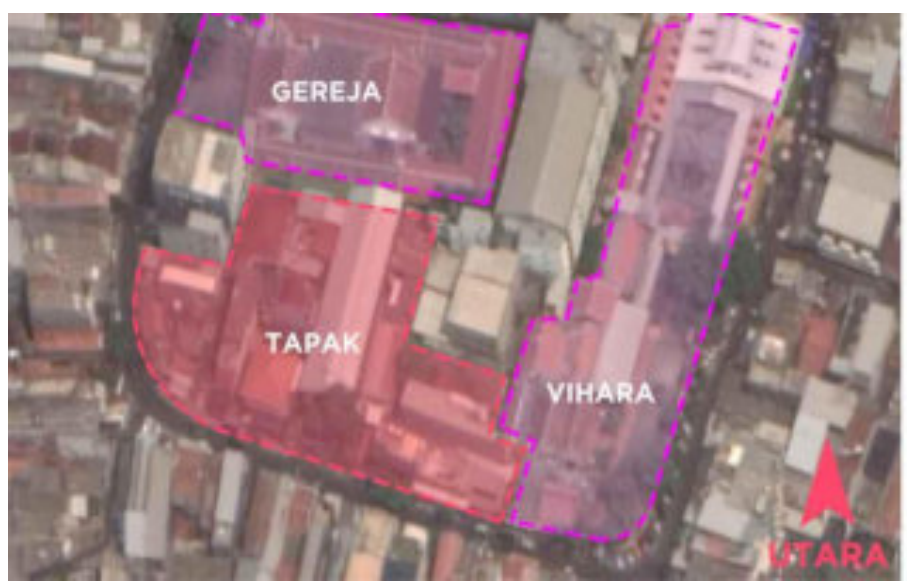

\section{DATA TAPAK SURFACE}

\section{ZONA CAMPURAN}

LUASAN $= \pm 4000 \mathrm{M} 2$

$\mathrm{KDB}=75$

$\mathrm{KLB}=3$

$\mathrm{KB}=4$

$\mathrm{KTB}=\mathbf{5 5}$

$\mathrm{KDH}=30$

$\mathrm{GSB}=5 \mathrm{M}$

Gambar 8. Data Tapak Surface

Sumber: Hasil olahan penulis, 2021

\section{Konsep Perancangan}

Lokasi di Glodok dipilih karna memiliki nilai sejarah, budaya dan ekonomi yang kuat. dapat dilihat dari diagram Echology ini, dimana banyaknya unsur-unsur yang saling berinteraksi, mempengaruhi, dan membentuk sebuah ekosistem. Dalam kawasan ini terdapat beberapa objek seperti pasar dan bangunan bersejarah yang sudah ada kemudian saya menginjeksi activator berupa nodes, lines, dan surfaces yang saling bersinggungan dengan program yang telah ada, hal-hal tersebut saling bergema sehingga membentuk sebuah Echology.

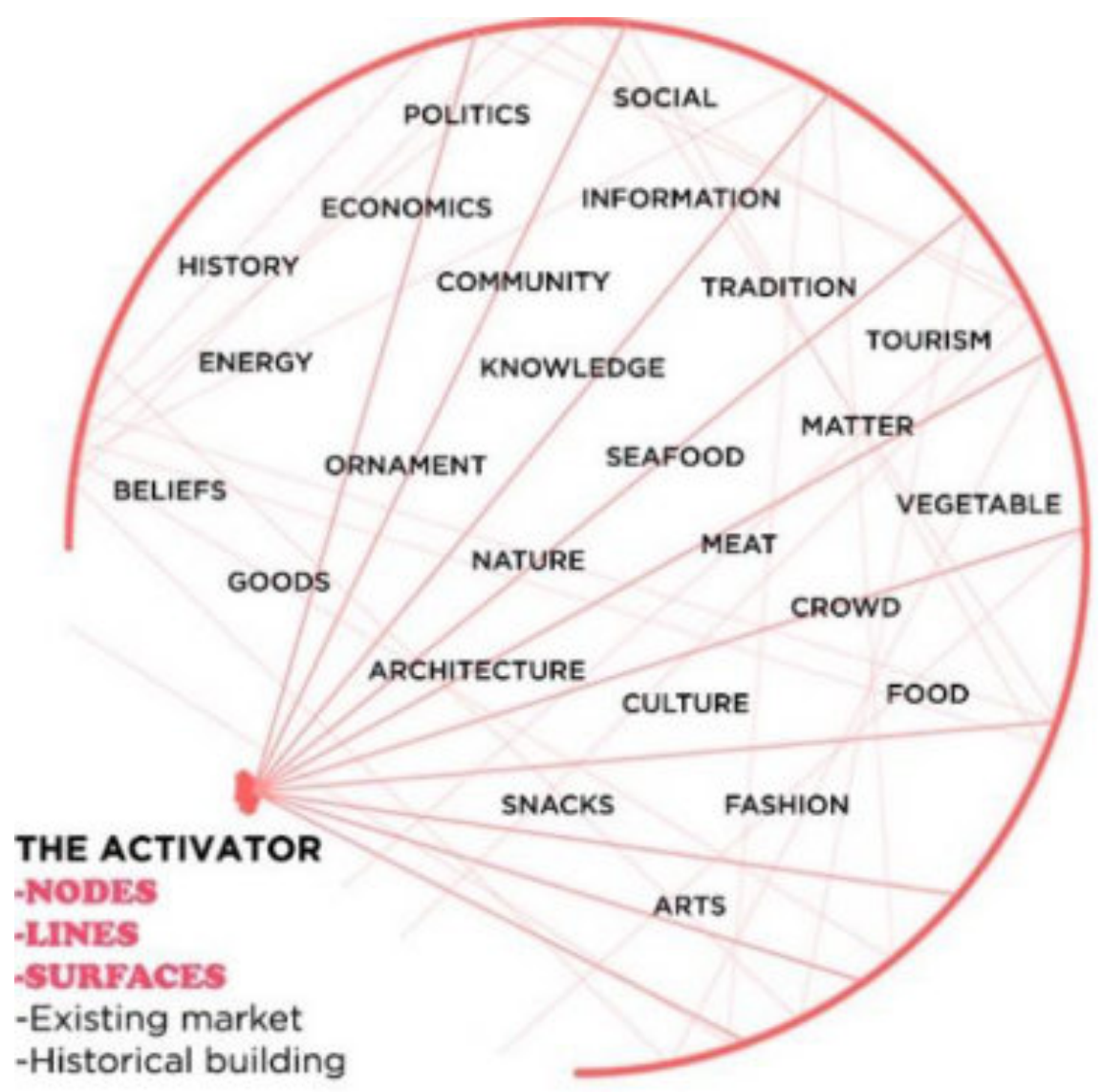

Gambar 9. Diagram Echology

Sumber: Hasil olahan penulis, 2021 
Kemudian melalui analisis program dengan menguraikan dan juga menghubungkan antar program eksisting yang ada saya mengklasifikasikan program-program yang sudah ada terhadap beberapa faktor seperti ekonomi, budaya, sejarah, utilitas, dan edukasi dari hal tersebut saya menentukan program yang mampu menjadi activator bagi kawasan ini serta mampu menyelesaikan berbagai isu yang ada.

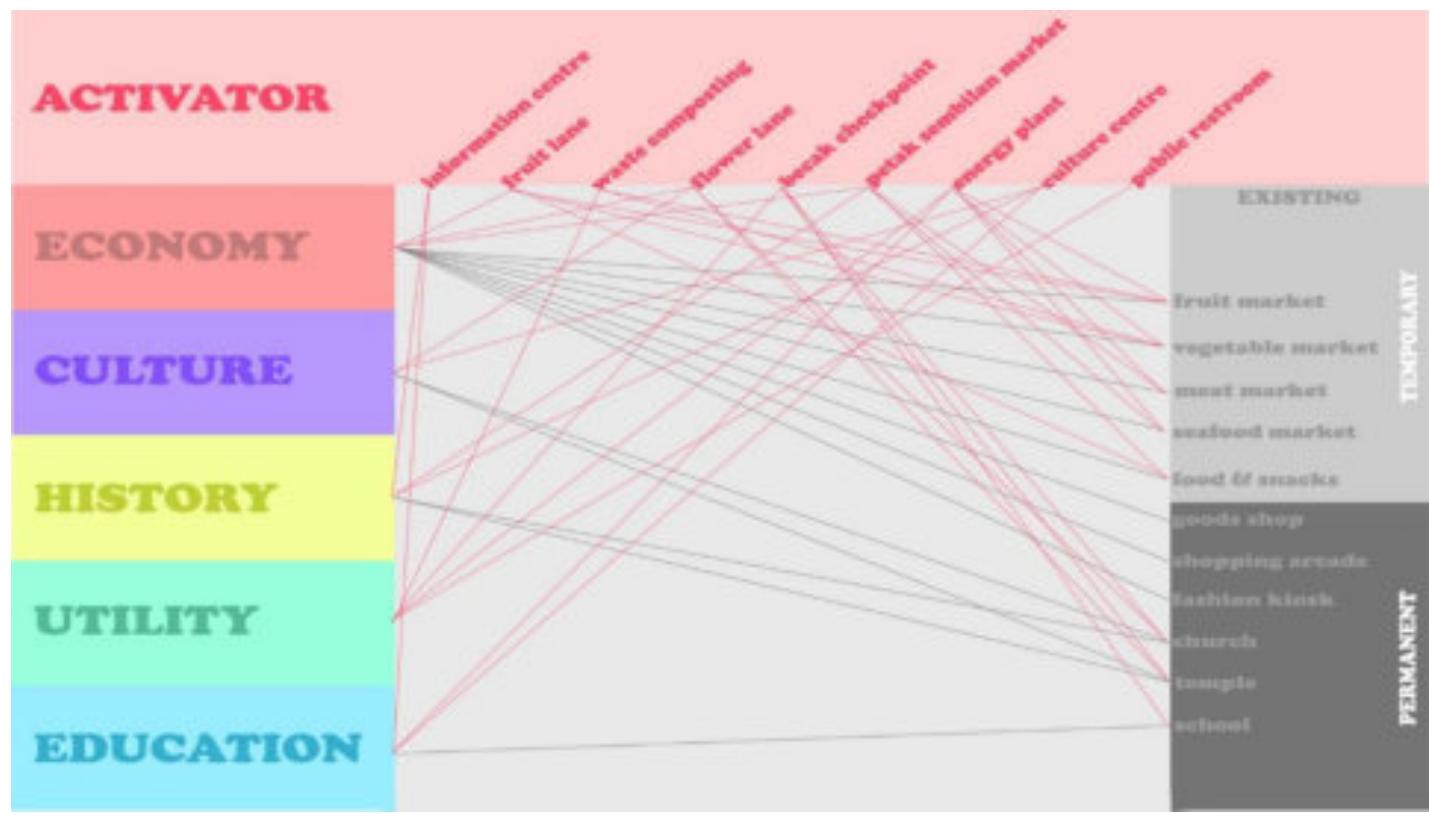

Gambar 10. Matriks Hubungan Antar Program

Sumber: Hasil olahan penulis, 2021

Analisa tapak dilakukan untuk menentukan titik-titik lokasi proyek yang terdiri dari 3 unsur yaitu Lines, Nodes dan Surfaces. Lines terdiri dari Petak Sembilan Market yang memiliki bagian pertokoan dan juga bagian lapak pasar basah, Fruit Lane yang berfungsi sebagai pasar buah maupun sayuran dan juga Flower Lane yang menjual bunga persembahan bagi pengunjung Vihara. Nodes terdiri dari beberapa titik yang tersebar pada kawasan ini seperti: Information Centre dengan Gate yang menyambut pengunjung, Public Restroom sebagai fasilitas publik, Waste Composting untuk mengolah limbah organik, Energy Plant yang menghasilkan energi terbarukan dan Becak Checkpoint sebagai fasilitas transportasi pada kawasan. Sedangkan untuk elemen Surface merupakan Culture Centre yang memiliki fungsi sebagai wadah komunitas dan perayaan budaya Tionghua bagi masyarakat pecinan Glodok dan sekitarnya.

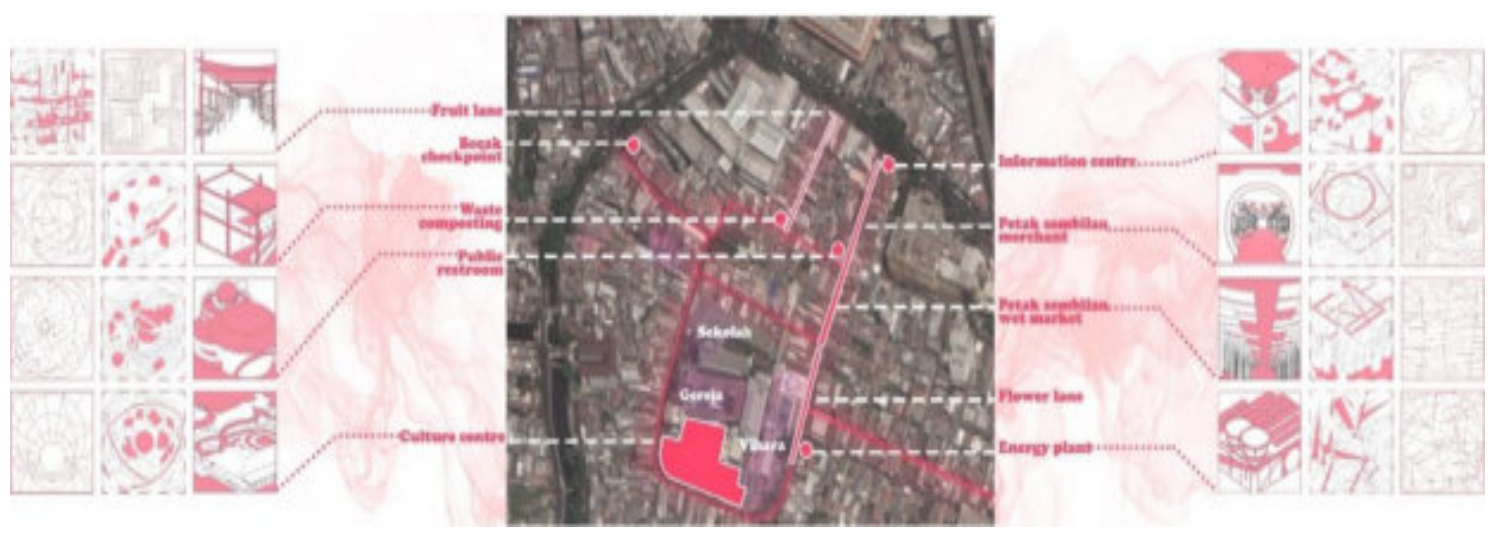

Gambar 11. Titik Lokasi Objek Arsitektur

Sumber: Hasil olahan penulis, 2021 
Dari metode desain yang digunakan, metode naratif transkrip menterjemahkan perjalanan sejarah budaya Tionghua di Indonesia menjadi garis, lalu menjadi bentuk, hingga menjadi objek Arsitektur. Setiap objek Arsitektur mereprentasikan sebuah masa yang diwujudkan dalam susunan massa bangunan, elemen-elemen pembentuk bangunan, hingga pengalaman ruang yang diberikan. Setiap objek memiliki karakteristiknya masing-masing sesuai dengan transkrip dan fungsinya.
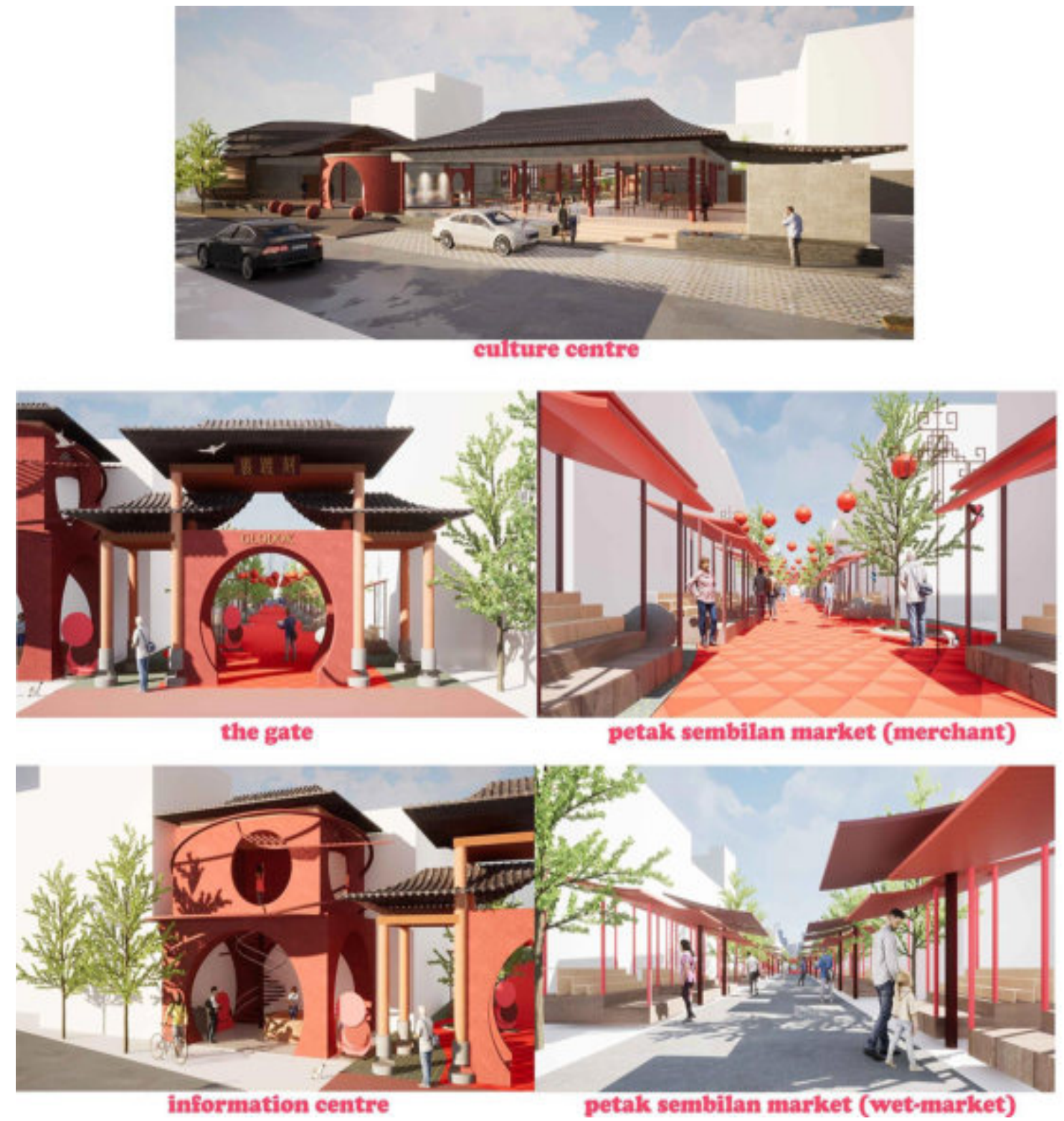

Gambar 12. Perspektif Objek Arsitektur

Sumber: Hasil olahan penulis, 2021

Dapat dilihat dari gambar diatas bahwa The Gate menjadi gerbang kawasan yang disambut dengan Petak Sembilan market. Pada sebelah The Gate terdapat Information Centre yang menjadi pos informasi kawasan bagi pengunjung serta terdapat juga wastafel outdoor untuk menjaga kebersihan dimasa pandemi. Sedangkan Petak Sembilan Market terbagi menjadi dua bagian yaitu Merchant dan Wet-Market. Pada bagian merchant, diterapkan teknologi Pavegen Kinetic Harvest yang mengubah pijakan kaki menjadi energi. Penempatan tersebut mempertimbangkan karena tempat ini memiliki frekuensi pergerakan pengunjung terbanyak. Lalu pada Wet-Market terdapat Sun Shading untuk mengurangi terik-nya sinar matahari. 
Meskipun proyek ini memiliki banyak objek dan komponen didalamnya, unsur Arsitektur Tionghua tetap diterapkan secara konsisten pada setiap objek arsitektur. Keselarasan ornamen serta penggunaan warna merah menjadi elemen penting dalam pembentukan citra kawasan Pecinan.

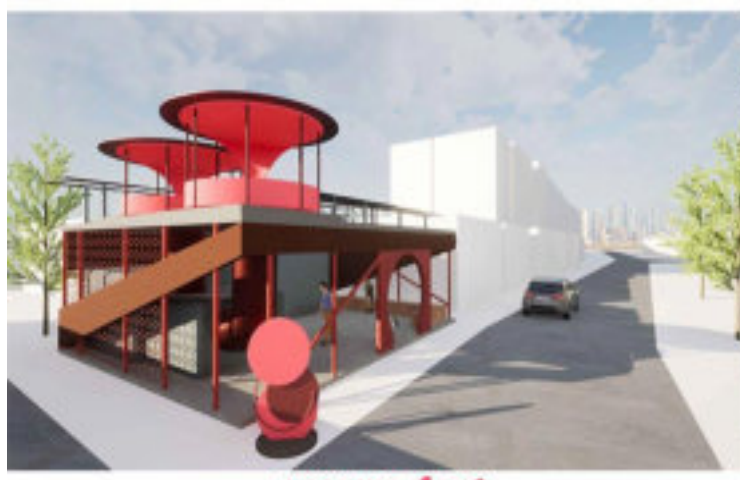

energy plant

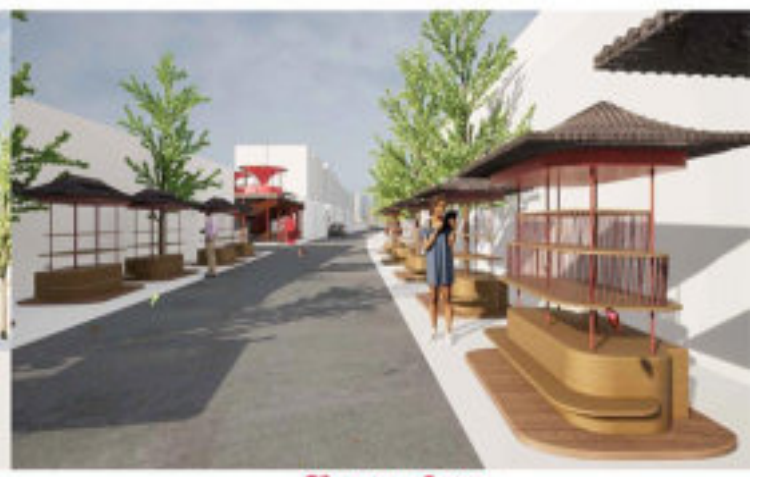

flower lane

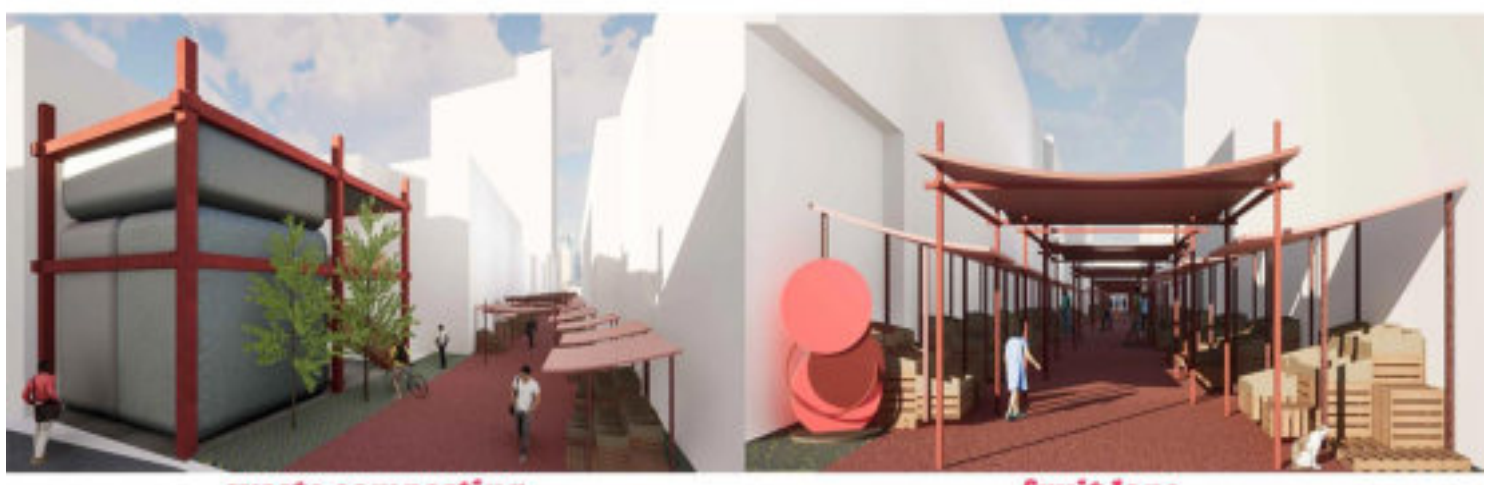

waste composting

fruit lane

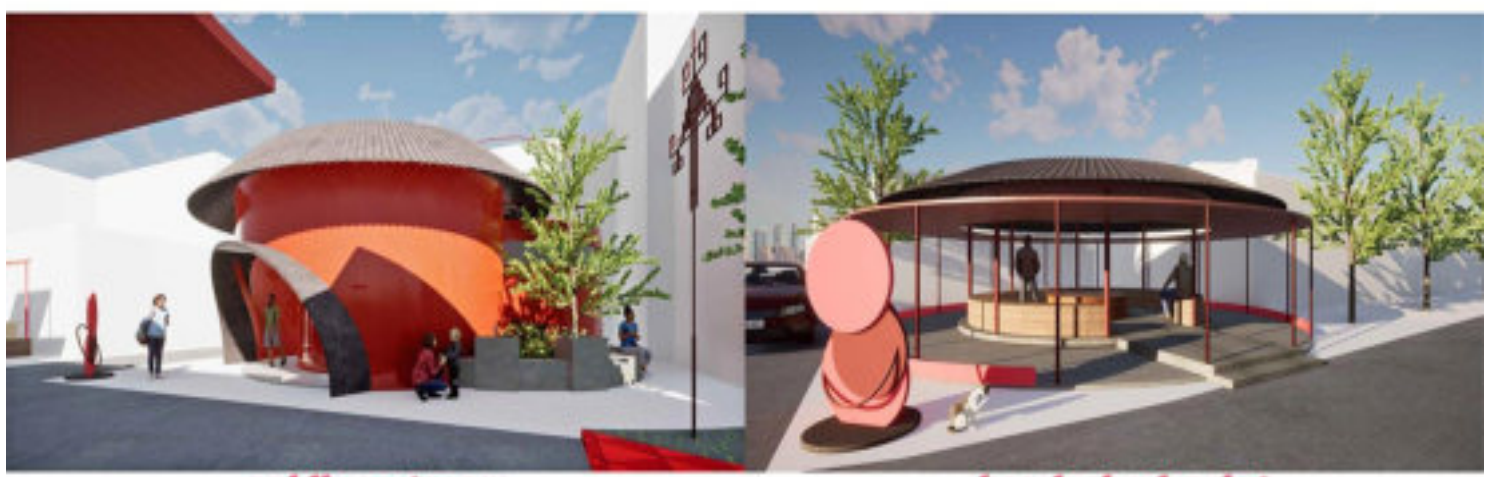

public restroom

becalk checkpoint

Gambar 13. Perspektif Objek Nodes dan Lines

Sumber: Hasil olahan penulis, 2021

Energy Plant menyambut pengunjung dari arah jalan Gajah mada. Pada Energy Plant terdapat teknologi Air Vortex Generator yang mampu menghisap dan meningkatkan kecepatan udara yang kemudian disalurkan ke turbin Generator sehingga mampu menghasilkan energi terbarukan. Selain itu penerapan panel surya dan ruang tunggu juga melengkapi objek ini. Flower Lane terletak pada depan Vihara Dharma Bhakti. Fungsinya sebagai tempat jual beli bunga dan juga pelepasan burung bagi umat Vihara yang ingin melakukan persembahan. Fruit Lane sebagai pasar buah dan sayuran yang memiliki tipologi gang dan berada diantara 2 sisi belakang ruko. Desain kios pada Fruit Lane didesain modular agar fleksibel, selaras serta efisien dalam ruang yang relatif sempit. Waste Composting terdapat diujung Fruit Lane dengan fungsi utamanya sebagai tempat mengelolah limbah organik dari pasar menjadi biogas yang kemudian 
dapat digunakan menjadi energi terbarukan. Public Restroom yang memiliki fungsi utilitas sebagai toilet umum bagi pengguna, tempat penitipan barang belanjaan, serta terdapat wastafel pada area outdoor. Becak Checkpoint yang terletak disamping jalan.Kemurnian juga memiliki fungsi utilitas sebagai fasilitas transportasi dalam kawasan Glodok.

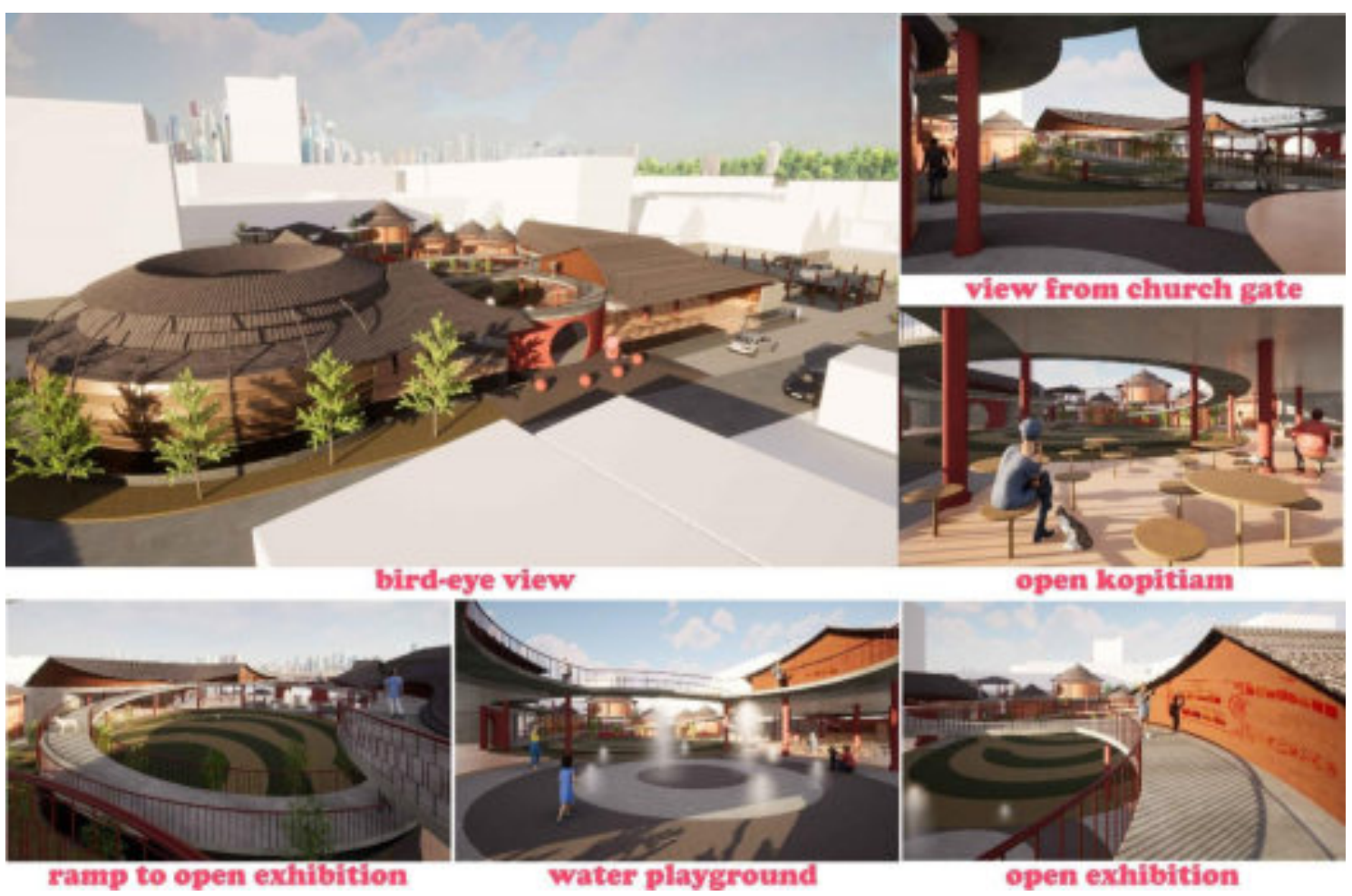

Gambar 14. Perspektif Culture Centre

Sumber: Hasil olahan penulis, 2021

Culture Centre yang memiliki fungsi sebagai wadah Komunitas, Budaya, serta ruang terbuka publik ini di desain sangat inklusif dan terbuka melalui bentuk sirkular yang memungkinkan interaksi yang fleksibel serta pengalaman ruang yang berbeda. Terdapat juga jalan penghubung langsung dari Gereja dan Vihara sebagai respon dari letaknya yang berada diantara bangunan keagamaan yang bersejarah. Akses masuk menuju Culture Centre ini difokuskan untuk pejalan kaki yang langsung disambut dengan Water Playground dan Open-Kopitiam sebagai tempat berkumpul dan ngobrol santai. Kemudian terdapat Auditorium, Hallway Gallery dan Pottery Workshop sebagai program dengan unsur seni. Ditengah bangunan juga terdapat Courtyard Garden yang memiliki Public Stage untuk pertunjukan keseniaan yang berada diluar ruangan. Lalu pada belakang tapak terdapat culture class sebagai sarana pembelajaran bahasa maupun budaya Tionghua pada kawasan ini. Terdapat ramp yang melingkari taman sebagai akses menuju Outdoor Exhibition yang berada di Rooftop. Outdoor Exhibition ini merupakan area pameran yang mengedukasi sejarah perjalanan budaya Tionghua di Indonesia. 


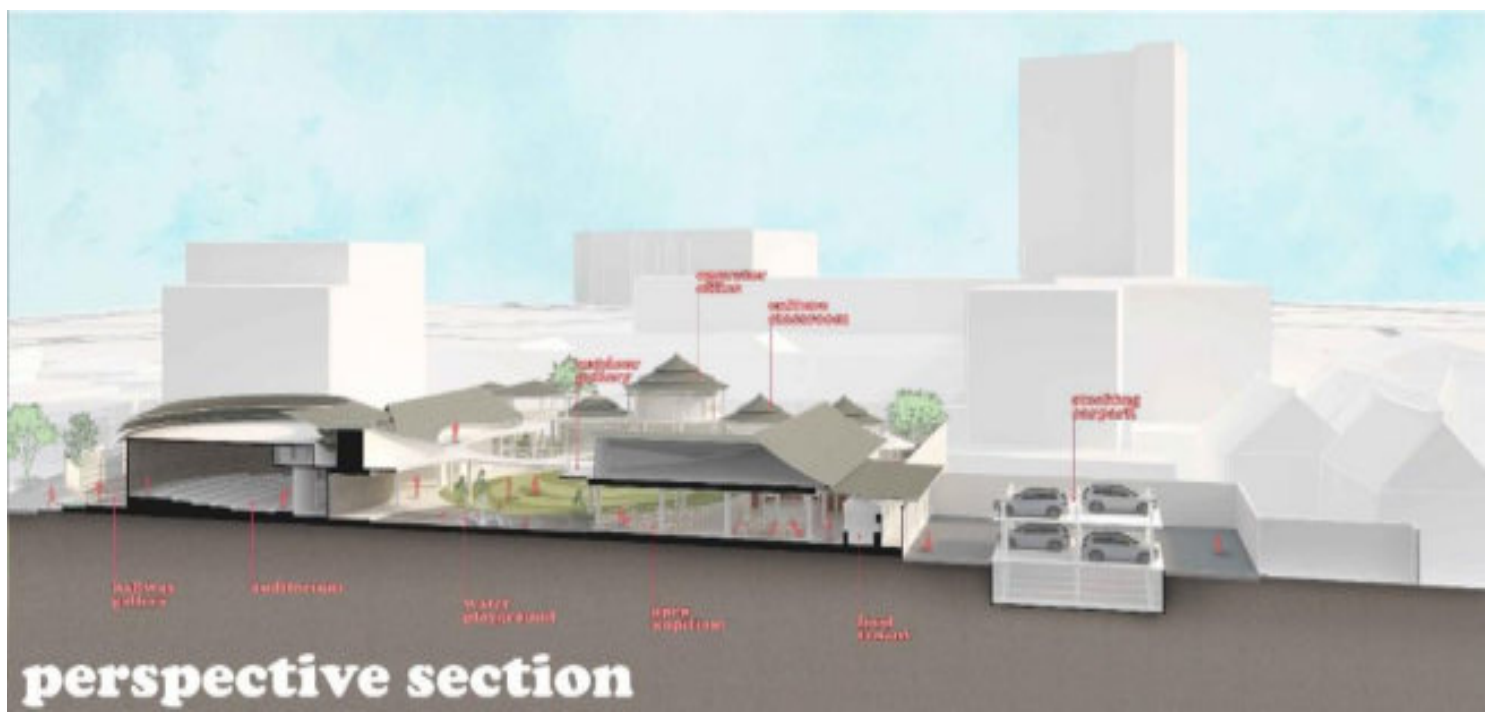

Gambar 15. Potongan Perspektif

Sumber: Hasil olahan penulis, 2021

Terdapat juga metode metafora dalam Culture Centre dimana bentuk atap dan susunan massa terinspirasi dari rumah adat komunitas suku Hakka, tipologi rumah Courtyard, dan juga atap paviliun. Selain itu ruang terbuka sebagai ruang hijau publik serta aktivitas budaya yang memerlukan outdoor yang luas. Elemen air yang ditambahkan sebagai intrepretasi dari sejarah asal-usul nama Glodok dan Pancoran dimana dulu terdapat sumber mata air yang terus memancur. Terdapat juga stacking parking dengan sistem hidrolik yang mampu meningkatkan lahan parkir hingga dua kali lipat.

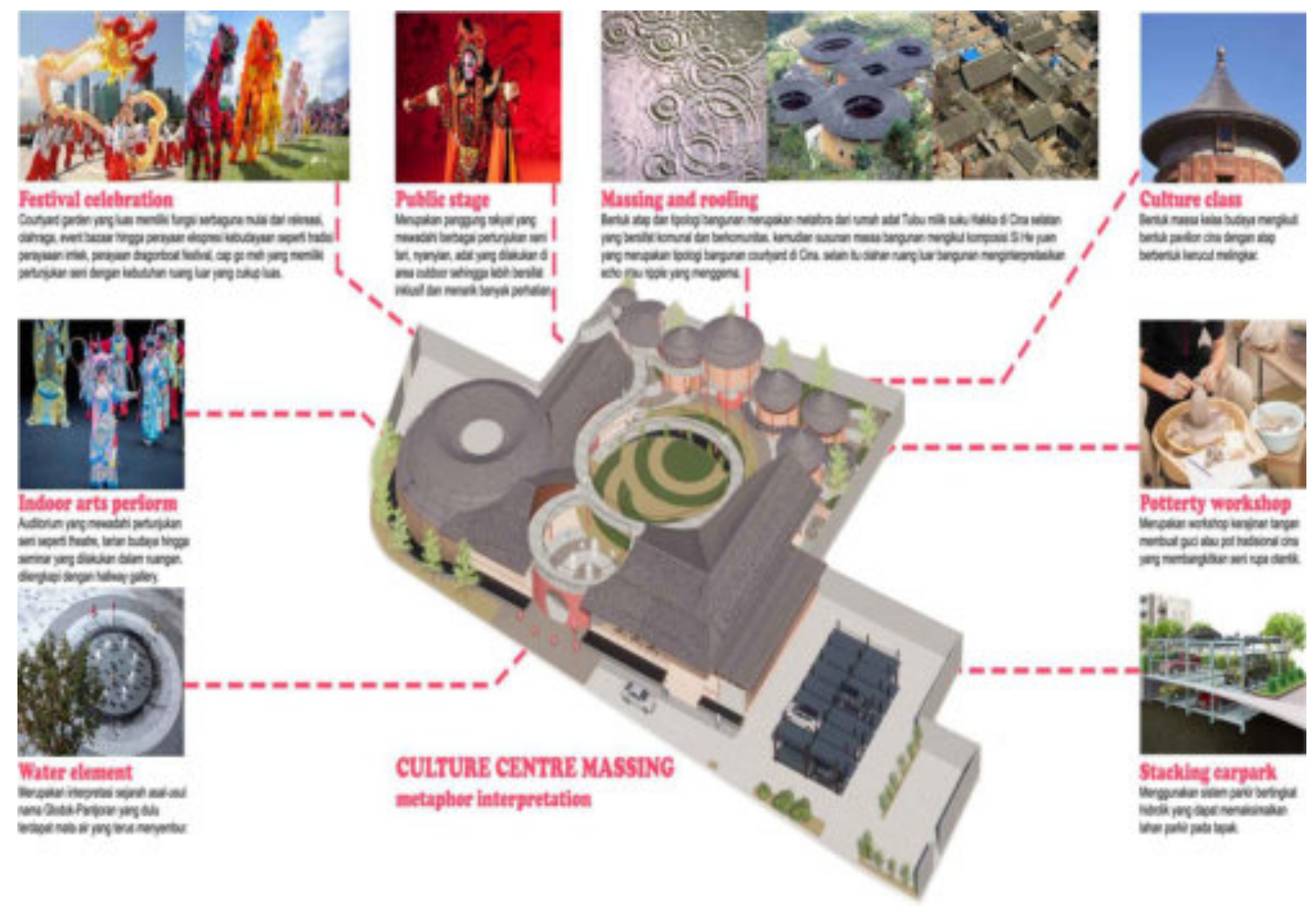

Gambar 16. Elemen Metafora

Sumber: Hasil olahan penulis, 2021 


\section{KESIMPULAN DAN SARAN}

\section{Kesimpulan}

Echo dalam arsitektur merupakan sebuah gaung yang berasal dari arsitektur yang memiliki nilai sejarah dan mulai memudar. Sebuah bangunan dapat dikaitkan dengan kenangan negatif masa lampau dan tetap merupakan bagian dari warisan budaya kota. Upaya mendamaikan masa lalu dengan masa kini dilakukan dengan memadukan Arsitektur kontemporer dan reruntuhan sejarah. Gerakan ini diwujudkan sebagai gaung yang menafsirkan kembali sejarah dalam istilah moderen. Gema dalam Arsitektur akan memberikan ruang yang berakar pada tradisi dan mengkomunikasikannya dalam bahasanya sendiri. Dalam konteks pecinan Glodok, kawasan ini memiliki banyak sejarah kelam yang sejalan dengan perjalanan budaya Tionghua di Indonesia. Permasalahan yang ada pada kawasan ini juga sangat kompleks dan beragam. Hal tersebut tidak dapat diselesaikan melaui satu bangunan saja, melainkan perlu nya sebuah jaringan ekosistem yang bersinergi. Konsep Echology mampu menjawab permasalah tersebut dengan struktur jaringan rhizome yang mampu mengintregasikan objek-objek Arstitektur secara Resillience dan berkelanjutan. Proyek ini juga mereimajikan kawasan pecinan Glodok menjadi sesuatu yang lebih, dimana aspek sejarah budaya ekonomi dapat tercerminkan dan membangun imaji Glodok yang baru dengan mempertimbangkan berbagai elemen yang ada pada kawasan serta merancangnya demi keberlangsungan di masa kini maupun masa depan. Pembentukan Arsitektur juga berasal dari transkrip naratif dari perjalanan budaya Tionghua di Indonesia sehingga memiliki sisi sejarah dan filosofis. Diharapkan proyek ini dapat menjadi contoh dan metode dalam menyelesaikan permasalahan bagi kawasan-kawasan bersejarah yang telah memudar pada masa yang akan datang.

\section{Saran}

Survei kualitatif dapat dilakukan lebih mendetail melalui pengumpulan data pada lapangan dan wawancara langsung terhadap pengunjung, keterbatasan mobilitas dikarenakan situasi pandemi saat ini membuat kurangnya data yang berkaitan dengan pengguna secara langsung. Diharapkan pada masa yang akan datang, survey dapat dilakukan dengan interaksi langsung dengan pengguna untuk mendapat data dari sisi sosial atau antroposentris.

\section{REFERENSI}

Ellis, J. (1986). "The Superstring: Theory of Everything, or of Nothing?". Nature, 323 (6089), 595598.

Hawking, S. W. (2006). The Theory of Everything: The Origin and Fate of the Universe. Phoenix Books: Special Anniv.

Lynch, K. (1960). The Image of The City. United States of America

Nio, J.L. (2013). Peradaban Tionghoa Selayang Pandang (pp. 28). Jakarta: KPG.

Pratiwo. (2010). Arsitektur Tradisional Tionghoa Dan Perkembangan Kota. Yogyakarta: Penerbit Ombak.

Wildana, K. (2007). Revitalisasi Kawasan Pecinan Sebagai Pusaka Kota (Urban Heritage). Makassar. 
